\title{
Effect of Yoga exercises on the course of pregnancy, labour and puerperium
}

\author{
Mohamed Abdelmoaty Elsamra \\ Assistant Professor, Dept. of Obstetrics and Gynaecology, University of Alexandria, Alexandria, Egypt
}

Corresponding Author:

Email: melsamra@yahoo.com

\begin{abstract}
Introduction: Pregnancy is a condition in which women undergo distinct physiological changes and stress. Also accompanied by unique physical and psychological demands, Yoga is thought to alter nervous system regulation and physiological system functioning (e.g. cardiovascular, gastrointestinal, endocrine and immune systems). It improves psychological wellbeing (e.g. frequency of positive mood states) and physical fitness (e.g. strength, flexibility).

Patients and Methods: 250 primigravida females selected from the antenatal clinic of El-Shatby Maternity University Hospital, and allocated into two groups; group A: 125 females who will practice Yoga exercises and group B: 125 females who will not practice any kind of exercises.

Results: Both groups are matched in age, height $(\mathrm{p}>0.05)$. Pulse, systolic, diastolic blood pressure and respiratory rate are matched in both groups $(\mathrm{p}>0.05)$. Incidence of edema, varicose vein, sleep disturbance, mood changes were significantly higher in group B $(\mathrm{p}<0.05)$. All women in group A had smooth course $(\mathrm{p}=0.000)$. Abnormal ultrasound findings, puerperium problems and mild postpartum hemorrhage were statistically significantly higher in group $B(p<0.05)$.

Conclusion: Prenatal Yoga is an excellent choice for any healthy woman to use in order to prepare herself physically and emotionally for child birth.
\end{abstract}

Keywords: Yoga.

\section{Introduction}

Yoga's history has many places of obscurity and uncertainty due to its oral transmission of sacred texts and the secretive nature of its teachings. The early writings on Yoga were transcribed on fragile palm leaves that were easily damaged, destroyed or lost. So the origin of Yoga is a matter of debate. There is no consensus on its chronology or specific origin other than that Yoga developed in ancient India. ${ }^{1}$ Suggested origins are the Indus Valley Civilization (3300-1900 BCE). ${ }^{1,2}$

Yoga means union. ${ }^{2}$ So, Yoga is referred as union of body, mind and spirit. This union could be achieved through the Yoga practices of specific postures (Asanas), breathing exercises (Pranayama), relaxation techniques (Pratyahara) and meditation (Dhyana). ${ }^{3}$

As pregnancy is a condition in which women undergo distinct physiological changes, stress and is accompanied by unique physical and psychological demands, ${ }^{4}$ it is claimed that maternal stress and anxiety during pregnancy is associated with a host of negative consequences for the fetus and subsequent development. ${ }^{5}$ It is hypothesized that maternal stress may affect the intrauterine environment and alter fetal development during critical periods. Through either activation of the placental stress system, causing the release of corticotrophin releasing hormone, or through diminished blood flow and oxygen to the uterus. ${ }^{6}$

Yoga exercises (Asanas and Pratyahara) can be helpful in the management of stress and other associated symptoms accompanying pregnancy, such as edema, gestational hypertension, diabetes, mood instability musculoskeletal discomfort, insomnia, aches and weight gain. ${ }^{7}$ It is of great importance to know that practicing gentle Yoga during pregnancy has shown many benefits with no recorded adverse effects. ${ }^{8}$

\section{Subjects and Methods}

Two hundred and fifty primigravida 14 weeks of gestation educated females were selected from the antenatal clinic of El-Shatby Maternity University Hospital. All are subjected to full history taken, full routine investigation (complete blood count, fasting blood sugar, liver and renal function tests). They were allocated into 2 groups:

I. Group A "study group": 125 women who practiced certain types of gentle Yoga including:

1. Asana: three sessions per week, duration ranged from 15 to 60 minutes per session.

a. Palm tree: woman stand upright, raise her arms overhead and interlock her fingers "as a palm tree swaying in the wind". Benefits: This poses stretch and strengthens the torso (Figure 1).

b. Modified triangle pose: woman stands with her feet wide apart and then stretch her left hand overhead and bend down to the right side and touch her knee. Then return to starting position and switch sides. Benefits: This pose regulates the digestive system and massages internal organs like the liver (Figure 2).

c. Modified forward bend: woman stands in front of chair, press her palms on the chair. Keep her back straight and bend from her hips, then return to standing position. Benefits: This pose stretches the back and legs (Fig. 3). 
These exercises were performed 3 times per week under supervision, starting slowly and relax for 3 minutes after every asana.

2. Pranayoma "Breathing exercises"

a. Long deep breathing.

b. Alternate nostril breath (Figure 4).

These exercises were done for 3-10 minutes.

II. Group B "control group" 125 women who did not practice any kind of exercises throughout the whole course of pregnancy.

All cases were subjected to:

i. Full investigation every 8 weeks.

ii. Abdominal ultrasound every 4 weeks.

iii. General examination and vital signs weekly till the end of pregnancy.

\section{Results}

Mean age was $24.46 \pm 2.26$ years in group A compared with $24.85 \pm 1.74$ years in group B with no significant difference $(\mathrm{p}=0.133)$. Mean height was $159.92 \pm 1.8 \mathrm{~cm}$ in group A compared with $160.30 \pm$ $1.92 \mathrm{~cm}$ in group B with no significant difference $(\mathrm{p}=0.108)$. Also, both groups are matched in pulse, systolic, diastolic blood pressure and respiratory rate are matched in both groups all over different time of measurements (every 4 weeks gestation starting from week 14) ( $\mathrm{p}>0.05)$.

Incidence of edema, varicose vein, sleep disturbance, mood changes were significantly higher in group B when compared with group A $(\mathrm{p}<0.05)$. All women in group A had smooth course compared with only $8(6.40 \%)$ in group B $(\mathrm{p}=0.000)$. Abnormal ultrasound findings, puerperium problems and mild postpartum hemorrhage were statistically significantly higher in group B compared with $0 \%$ in group A $(p<0.05) .48(38.40 \%)$ of group B women had CS, compared with $27(21.60 \%)$ in group A $(p=0.004)$ (Table I).

Table 1: Outcome in both Yoga and No yoga group

\begin{tabular}{|l|c|c|c|}
\hline & $\begin{array}{c}\text { Group A } \\
\text { Yoga group } \\
(\mathrm{n}=125)\end{array}$ & $\begin{array}{c}\text { Group B } \\
\text { No Yoga group } \\
(\mathrm{n}=125)\end{array}$ & $\begin{array}{c}\text { Test of significance } \\
(\boldsymbol{p} \text { value })\end{array}$ \\
\hline Edema & $0(0.00 \%)$ & $101(80.80 \%)$ & $\mathrm{X}^{2}=169.463, \mathrm{p}=0.000^{*}$ \\
\hline Varicose vein & $0(0.00 \%)$ & $67(53.60 \%)$ & $\mathrm{X}^{2}=91.530, \mathrm{p}=0.000^{*}$ \\
\hline Sleep disturbance & $119(95.20 \%)$ & $125(100.00 \%)$ & $\mathrm{X}^{2} \mathrm{Y}=4.269, \mathrm{p}_{\mathrm{Y})}=0.039^{*}$ \\
\hline Mood changes & $104(83.20 \%)$ & $125(100.00 \%)$ & $\mathrm{X}^{2}=22.926, \mathrm{p}=0.000^{*}$ \\
\hline Abnormal U/S findings & $0(0.00 \%)$ & $7(5.60 \%)$ & $\mathrm{X}_{(\mathrm{Y})}=5.291, \mathrm{p}_{\mathrm{Y})}=0.021^{*}$ \\
\hline Smooth course & $125(100.00 \%)$ & $8(6.40 \%)$ & $\mathrm{X}^{2}=219.925, \mathrm{p}=0.000^{*}$ \\
\hline $\begin{array}{l}\text { Mode of delivery: } \\
\text { i. NVD } \\
\text { ii. CS }\end{array}$ & $98(78.40 \%)$ & $77(61.60 \%)$ & $\mathrm{X}^{2}=8.400, \mathrm{p}=0.004^{*}$ \\
\hline Puerperium problems & $27(21.60 \%)$ & $48(38.40 \%)$ & \\
\hline Mild postpartum hemorrhage & $0(0.00 \%)$ & $6(4.80 \%)$ & $\mathrm{X}_{(\mathrm{Y})}=4.269, \mathrm{p}_{(\mathrm{Y})}=0.039^{*}$ \\
\hline
\end{tabular}

Y: Yate's (continuity correction) for Pearson Chi-Square test

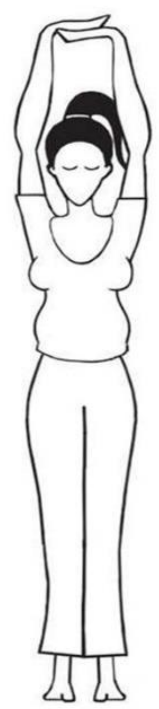

Fig. 1: Palm tree exercise 


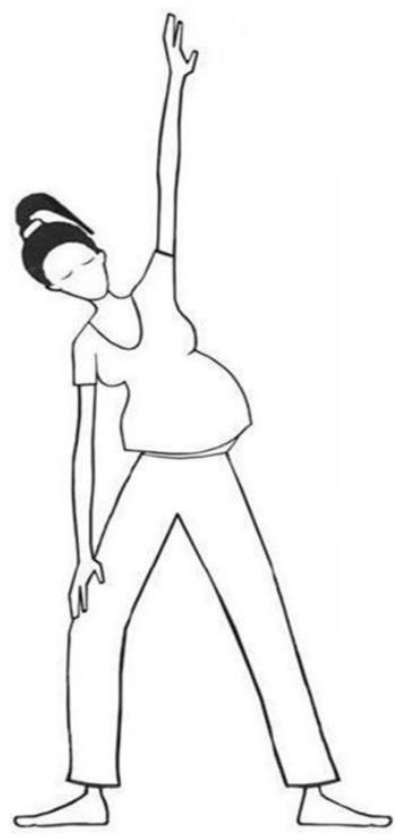

Fig. 2: Modified triangle pose

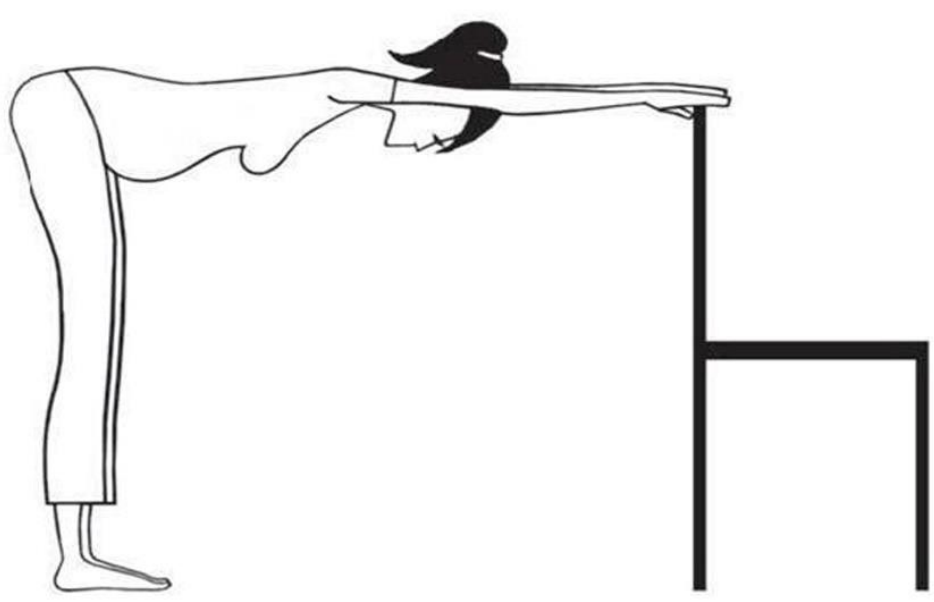

Fig. 3: Modified forward bend 


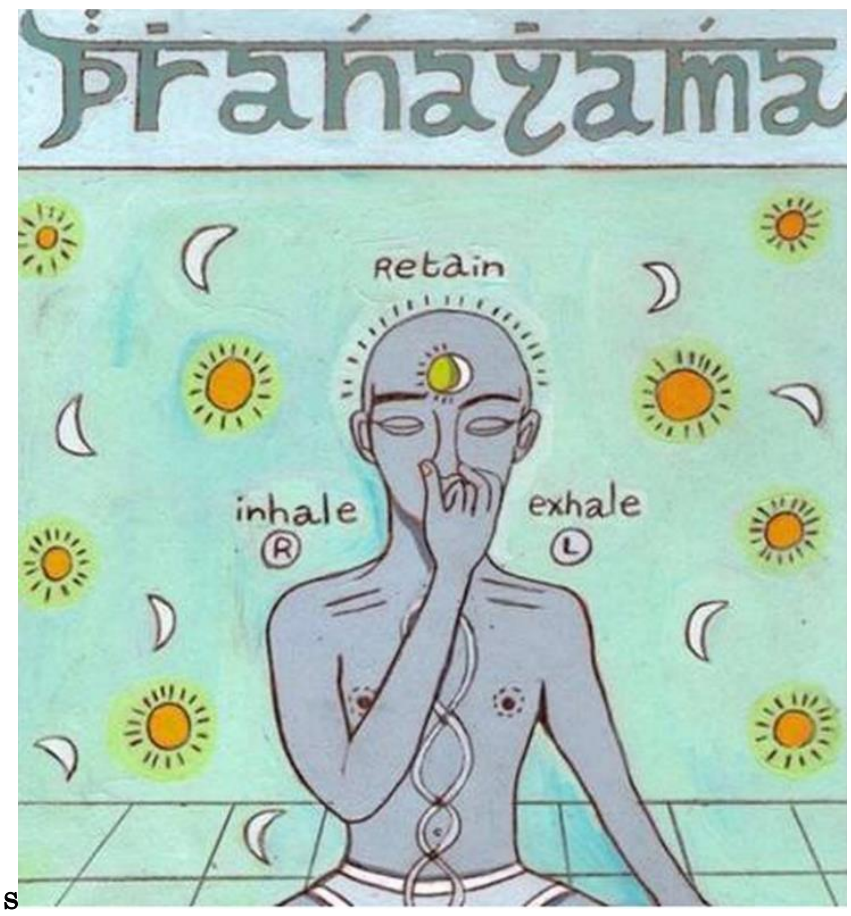

Fig. 4: Alternate nostril breath

\section{Discussion}

Previous researches showed that exercises during pregnancy can be beneficial to both mother and fetus. ${ }^{910}$ There was no adverse effects of Yoga exercises during pregnancy, this result is in line with those of Sun et al. ${ }^{11}$

Although prenatal Yoga has been shown to decrease excessive weight and to improve cardiovascular health according to Babbar et al, ${ }^{12}$ and to increase heart rate range according to Satyapriya et al. ${ }^{13}$ But in our study, there were no significant difference between who practiced Yoga and who did not practice it as regards blood pressure or heart rate changes, but there were marked decrease in the occurrence varicose veins and oedema among Yoga practicers.

Our study shows that a single session of Yoga can reduce anxiety, improve mood and insomnia and that these effects remain after repeated sessions. Similar results were reported in 1990 by Allolio et al. ${ }^{14}$

There were no obvious differences in the mode of delivery although the incidence of normal vaginal delivery was higher among Yoga practicers but was not statistically significant.

Rakhshani et al., found that women who practice Yoga during their prenatal period have significantly decreased risk of hypertension, gestational diabetes and intrauterine growth restriction. ${ }^{15}$

\section{Conclusion}

Mind-body practices that cultivate general health, diminish distress, and increase self-awareness during prenatal Yoga exercise with be particularly effective in addressing both physical and psycho-emotional aspects of pregnancy and labour.

\section{References}

1. Flood GD. An introduction to Hinduism: Cambridge University Press; 1996.

2. Crangle EF. The origin and development of early Indian contemplative practices: Otto Harrassowitz Verlag;1994.

3. Salmon P, Lush E, Jablonski M, Sephton SE. Yoga and mindfulness: Clinical aspects of an ancient mind/body practice. Cognitive and Behavioral Practice. 2009; 16(1):59-72.

4. Beddoe AE, Lee KA. Mind-body interventions during pregnancy. Journal of Obstetric, Gynecologic, \& Neonatal Nursing. 2008; 37(2):165-75.

5. Sandman CA, Davis EP, Buss C, Glynn LM. Prenatal programming of human neurological function. International journal of peptides. 2011;2011.

6. Fink NS, Urech C, Isabel F, Meyer A, Hoesli I, Bitzer $\mathrm{J}$, et al. Fetal response to abbreviated relaxation techniques. A randomized controlled study. Early human development. 2011;87(2):121-7.

7. Melzer K, Schutz Y, Soehnchen N, Othenin-Girard V, de Tejada BM, Irion O, et al. Effects of recommended levels of physical activity on pregnancy outcomes. American journal of obstetrics and gynecology. 2010;202(3):266.e1-. e6.

8. Narendran S, Nagarathna R, Narendran V, Gunasheela $S$, Nagendra HRR. Efficacy of yoga on pregnancy outcome. Journal of Alternative \& Complementary Medicine. 2005; 11(2):237-44.

9. Paisley J, Mellion M. Exercise during pregnancy. American family physician. 1988;38(5):143-50.

10. Clapp JF. Exercise during pregnancy: a clinical update. Clinics in sports medicine. 2000;19(2):273-86.

11. Sun Y-C, Hung Y-C, Chang Y, Kuo S-C. Effects of a prenatal yoga programme on the discomforts of 
pregnancy and maternal childbirth self-efficacy in Taiwan. Midwifery.2010;26(6):e31-e6.

12. Babbar S, Parks-Savage AC, Chauhan SP. Yoga during pregnancy: a review. American journal of perinatology. 2012;29(06):459-64.

13. Satyapriya M, Nagendra HR, Nagarathna R, Padmalatha V. Effect of integrated yoga on stress and heart rate variability in pregnant women. International Journal of Gynecology \& Obstetrics. 2009;104(3):21822.

14. ALLOLIO B, HOFFMANN J, Linton E, WINKELMANN W, KUSCHE M, SCHULTE HM.

Diurnal salivary cortisol patterns during pregnancy and after delivery: relationship to plasma corticotrophin-releasing-hormone. Clinical endocrinology. 1990;33(2):279-89.

15. Rakhshani A, Nagarathna R, Mhaskar R, Mhaskar A, Thomas A, Gunasheela S. The effects of yoga in prevention of pregnancy complications in high-risk pregnancies: a randomized controlled trial. Preventive medicine. 2012;55(4):333-40. 